\title{
Prevotella multiformis sp. nov., isolated from human subgingival plaque
}

\author{
Mitsuo Sakamoto, ${ }^{1}$ Yi Huang, ${ }^{2}$ Makoto Umeda, ${ }^{2}$ Isao Ishikawa ${ }^{2}$ \\ and Yoshimi Benno ${ }^{1}$ \\ ${ }^{1}$ Microbe Division/Japan Collection of Microorganisms, RIKEN BioResource Center, Wako, \\ Saitama 351-0198, Japan \\ ${ }^{2}$ Division of Periodontology, Department of Hard Tissue Engineering, Graduate School, Tokyo \\ Medical and Dental University, Bunkyo-ku, Tokyo 113-8549, Japan
}

Correspondence

Mitsuo Sakamoto

sakamoto@jcm.riken.jp
During a study of novel oral phylotypes associated with periodontitis (Sakamoto et al., 2002a), we isolated, from the human oral cavity, a number of strains that were obligately anaerobic, non-pigmented, non-spore-forming, non-motile, Gram-negative rods. These isolates were phenotypically related to the genus Prevotella. Prevotella species are mainly isolated from the oral cavity, and some species are associated with periodontitis. 16S rRNA gene sequence analysis showed that each of the isolates was a member of the genus Prevotella. These strains were

Published online ahead of print on 5 November 2004 as DOI 10.1099/ ijs.0.63451-0.

Abbreviations: G6PDH, glucose-6-phosphate dehydrogenase; $6 \mathrm{PGDH}$, 6-phosphogluconate dehydrogenase.

The GenBank/EMBL/DDBJ accession numbers for the 16S rRNA gene sequences of $P$. multiformis strains PPPA $21^{\top}$, PPPA19, PPPA28 and PPPA30 are AB182483-AB182486.

Photomicrographs of $P$. multiformis cells from EG agar, an extended phylogenetic tree and tables of phenotypic and biochemical characteristics and cellular fatty acid compositions are available as supplementary material in IJSEM Online. divided into four groups: group 1 (one strain) was related to Prevotella loescheii with about $95 \%$ similarity; group 2 (one strain) was related to Prevotella oris with about $94 \%$ similarity; group 3 (four strains) was related to Prevotella denticola with $95 \%$ similarity; and group 4 (six strains) was related to Prevotella dentalis with $89 \%$ similarity. We have already proposed that groups 1 and 2 should be classified as two novel species of the genus Prevotella, Prevotella shahii and Prevotella salivae, respectively (Sakamoto et al., 2004). The present study was designed to determine the taxonomic status of group 3. On the basis of the results presented here, we propose that these strains should be classified as a novel species of the genus Prevotella, Prevotella multiformis sp. nov.

The strains used in the present study were maintained on Eggerth Gagnon (EG) agar (Merck) supplemented with $5 \%$ $(\mathrm{v} / \mathrm{v})$ horse blood for 2 days at $37^{\circ} \mathrm{C}$ in an atmosphere containing $100 \% \mathrm{CO}_{2}$. Strains PPPA19, PPPA $21^{\mathrm{T}}$, PPPA 28 and PPPA30 were isolated, on EG agar, from subgingival plaque from a patient with chronic periodontitis. Growth of the isolates on Bacteroides bile aesculin agar (Shah, 1992) was tested. 
Physiological reactions were determined with an API 20A anaerobic test kit in duplicate as recommended by the manufacturer (bioMérieux). The metabolic end-products were prepared as described previously (Holdeman et al., 1977) and were analysed by GLC (GC-7A; Shimadzu) using a $2.1 \mathrm{~m}$ glass column $(2 \cdot 8 \mathrm{~mm}$, FAL-M $25 \%$, Chromosorb W, 80/100 mesh, AW-DMCS $\mathrm{H}_{3} \mathrm{PO}_{4}$; Shimadzu). Fatty acid methyl esters were obtained from about $40 \mathrm{mg}$ wet cells by saponification, methylation and extraction using minor modifications (Kuykendall et al., 1988) of the method of Miller (1982). Cellular fatty acid profiles were determined by using the MIDI microbial identification system (Microbial ID). Isoprenoid quinones were extracted as described previously by Komagata \& Suzuki (1987) and were analysed by HPLC with a Cosmosil $5 \mathrm{C}_{18}$ column $(4.6 \times 150 \mathrm{~mm}$; Nacalai Tesque). Glucose-6-phosphate dehydrogenase (G6PDH), 6-phosphogluconate dehydrogenase (6PGDH), malate dehydrogenase and glutamate dehydrogenase activities were determined spectrophotometrically as described previously (Gharbia \& Shah, 1991; Bailey \& Love, 1995). API ZYM and API An-Ident enzymic substrate tests were performed in duplicate as recommended by the manufacturer (bioMérieux). Chromosomal DNA was isolated by using previously described methods (Marmur, 1961; Saito \& Miura, 1963), with some modifications. The DNA G $+\mathrm{C}$ content was determined by using the HPLC method of Tamaoka \& Komagata (1984), with some modifications. DNA-DNA hybridization experiments were carried out in microplate wells, as described by Ezaki et al. (1989). Hybridization was performed at $45^{\circ} \mathrm{C}$ for $16 \mathrm{~h}$. The 16S rRNA gene was analysed as described previously (Sakamoto et al., 2002b). The previously determined 16S rRNA gene sequences used for comparisons in this study were retrieved from the DDBJ, EMBL and GenBank nucleotide sequence databases. Sequence data were aligned using the CLUSTAL $\mathrm{W}$ program (Thompson et al., 1994) and corrected by manual inspection. Nucleotide substitution rates ( $K_{\text {nuc }}$ values) were calculated (Kimura, 1980) after gaps and unknown bases had been eliminated. The phylogenetic tree was constructed by the neighbourjoining method (Saitou \& Nei, 1987). Bootstrap resampling analysis (Felsenstein, 1985) was performed to estimate the confidence of tree topologies.

Strains PPPA19, PPPA21 $1^{\mathrm{T}}$, PPPA28 and PPPA30 were obligately anaerobic, non-spore-forming, non-motile, Gram-negative rods or cocci (coccobacilli). Cells on EG agar were $0 \cdot 5-0 \cdot 8 \times 1 \cdot 6-6.6 \mu \mathrm{m}$ or $0 \cdot 8 \times 0 \cdot 9-1 \cdot 0 \mu \mathrm{m}$ and occurred singly (see Supplementary Fig. A available in IJSEM Online). Colonies were 1-2 $\mathrm{mm}$ in diameter, grey to light brown, circular, entire, slightly convex and smooth on EG agar plates. Colonies of different sizes were detected on EG agar plates for all four strains. The cells forming large colonies were cocci, whereas those forming small colonies were cocci and rods. These four strains did not hydrolyse aesculin on Bacteroides bile aesculin agar, whereas P. loescheii JCM $8530^{\mathrm{T}}$, Prevotella oralis JCM 6330, P. oris JCM $8540^{\mathrm{T}}, P$. salivae JCM $12084^{\mathrm{T}}$ and Prevotella veroralis
JCM $6290^{\mathrm{T}}$ hydrolysed aesculin on the same agar plates. Growth of the isolates and other Prevotella species was inhibited on Bacteroides bile aesculin agar. The results of phenotypic tests are given in the species description below, while the phenotypic characteristics of the other Prevotella species are available in Supplementary Table A. The phenotypic characteristics of strains PPA19, PPPA $21^{\mathrm{T}}$, PPPA28 and PPPA30 were similar to those of $P$. denticola JCM 8528. These strains could be differentiated from $P$. denticola JCM 8528 by aesculin hydrolysis and D-cellobiose fermentation in API 20A tests.

The cellular fatty acid composition of Bacteroides species has been determined (Mayberry et al., 1982; Miyagawa et al., 1979; Shah \& Collins, 1980) and was reviewed for the classification of the genus Bacteroides (Shah \& Collins, 1983). In this study, the cellular fatty acid compositions of strains PPA19, PPPA $21^{\mathrm{T}}$, PPPA28 and PPPA30 were found to be very similar to that of $P$. denticola JCM 8528 . These four strains and $P$. denticola JCM 8528 contain greater relative amounts of anteiso-15:0 $(\geqslant 30 \%)$ than do other Prevotella species. The findings are summarized in the species description. In addition, the cellular fatty acid compositions of other Prevotella species are available in Supplementary Table B.

The major menaquinones of the clinical isolates and the other Prevotella species were MK-10 and MK-11. This result supports findings reported previously (Shah \& Collins, 1980, 1983). In our study, only the clinical isolates possessed MK-13 (Table 1).

The dehydrogenase enzyme pattern is an important criterion that differentiates the genus Bacteroides sensu stricto from other Gram-negative, anaerobic, non-sporeforming rods (Shah \& Collins, 1989; Shah, 1992). Bacteroides fragilis and related species possess enzymes of the hexose monophosphate shunt/pentose phosphate pathway, such as G6PDH, 6PGDH, malate dehydrogenase and glutamate dehydrogenase. Shah \& Collins $(1988,1990)$ proposed the new genera Porphyromonas and Prevotella because of the lack of particular enzymes (G6PDH and 6PGDH). In the present study, G6PDH and 6PGDH activities were not detected in extracts of the clinical isolates or the other Prevotella species. On the other hand, both malate dehydrogenase and glutamate dehydrogenase activities were detected in extracts of all strains tested.

The API ZYM and API An-Ident systems have been reported to be useful in the identification of oral and non-oral Gram-negative bacteria (Laughon et al., 1982; Slots, 1981; Tanner et al., 1985). In addition, the RapIDANA system (Innovative Diagnostics Systems) has been reported to be helpful in the identification of some phenotypically similar bile-inhibited Bacteroides species (Dellinger \& Moore, 1986). The biochemical characteristics of the clinical isolates and the other Prevotella species are available in Supplementary Table C. All strains were tested with API ZYM and API An-Ident. The biochemical 
Table 1. Menaquinone compositions of strains of $P$. multiformis sp. nov. and related species

Values are percentages of total menaquinones.

\begin{tabular}{|c|c|c|c|c|c|c|}
\hline Strain & MK-8 & MK-9 & MK-10 & MK-11 & MK-12 & MK-13 \\
\hline Prevotella multiformis PPPA19 & & 1 & 9 & 55 & 30 & 2 \\
\hline Prevotella multiformis PPPA $21^{\mathrm{T}}$ & & 1 & 9 & 54 & 31 & 3 \\
\hline Prevotella multiformis PPPA28 & 1 & 1 & 12 & 49 & 29 & 3 \\
\hline Prevotella multiformis PРPA30 & & 1 & 8 & 55 & 31 & 3 \\
\hline Prevotella bivia JCM $6331^{\mathrm{T}}$ & & 5 & 70 & 23 & & \\
\hline Prevotella corporis JCM $8529^{\mathrm{T}}$ & & & 5 & 74 & 20 & \\
\hline Prevotella denticola JCM 8528 & & & 6 & 61 & 32 & \\
\hline Prevotella loescheii JCM $8530^{\mathrm{T}}$ & & & 100 & & & \\
\hline Prevotella melaninogenica JCM $6325^{\mathrm{T}}$ & & & 61 & 39 & & \\
\hline Prevotella nigrescens JCM $6322^{\mathrm{T}}$ & & & 22 & 56 & 22 & \\
\hline Prevotella oralis JCM 6330 & 2 & 3 & 36 & 47 & 8 & \\
\hline Prevotella oris $\mathrm{JCM} 8540^{\mathrm{T}}$ & & & 17 & 57 & 26 & \\
\hline Prevotella salivae JCM $12084^{\mathrm{T}}$ & & & 13 & 67 & 20 & \\
\hline Prevotella shahii JCM $12083^{\mathrm{T}}$ & 1 & 1 & 18 & 58 & 22 & \\
\hline Prevotella veroralis JCM $6290^{\mathrm{T}}$ & & & 49 & 44 & 6 & \\
\hline
\end{tabular}

characteristics of strains PPA19, PPPA $21^{\mathrm{T}}$, PPPA28 and PPPA30 were similar to those of Prevotella bivia JCM $6331^{\mathrm{T}}$ and $P$. denticola JCM 8528. However, these four strains could be differentiated from $P$. bivia JCM $6331^{\mathrm{T}}$ and $P$. denticola JCM 8528 by API An-Ident tests. $\alpha$-Galactosidase and arginine and glycine aminopeptidase activities were helpful in the differentiation of these species (Table 2).
The DNA G + C contents of strains PPA19, PPPA $21^{\mathrm{T}}$, PPPA28 and PPPA30 were in the range $51 \cdot 1-51 \cdot 3 \mathrm{~mol} \%$. These values are slightly higher than that of $P$. denticola JCM 8528, which was phenotypically related to the clinical isolates (Table 2). The levels of DNA relatedness among the isolates were above $81 \%$ (81-98\%). The levels of DNA relatedness observed demonstrate the genomic distinction

Table 2. Differential characteristics of $P$. multiformis sp. nov. and some related Prevotella species

Species: 1, P. multiformis sp. nov.; 2, P. bivia; 3, P. denticola; 4, P. melaninogenica. Symbols: +, positive; - , negative; $\mathrm{W}$, weak. $\mathrm{V}$, variable.

\begin{tabular}{|c|c|c|c|c|}
\hline Characteristic & 1 & 2 & 3 & 4 \\
\hline Aesculin hydrolysis & - & - & + & - \\
\hline \multicolumn{5}{|l|}{ API 20A: } \\
\hline Sucrose & + & - & + & + \\
\hline Glycerol & + & - & + & - \\
\hline D-Cellobiose & + & - & - & - \\
\hline D-Raffinose & + & - & + & + \\
\hline \multicolumn{5}{|l|}{ API ZYM: } \\
\hline$\alpha$-Galactosidase & - & - & - & $\mathrm{w}$ \\
\hline$\beta$-Galactosidase & + & + & $\mathrm{w}$ & + \\
\hline$\alpha$-Fucosidase & $\mathrm{V}$ & + & $\mathrm{w}$ & + \\
\hline \multicolumn{5}{|l|}{ API An-Ident: } \\
\hline$\beta$-Glucosidase & - & - & - & $\mathrm{w}$ \\
\hline$\alpha$-Galactosidase & - & $\mathrm{w}$ & $\mathrm{w}$ & + \\
\hline$\beta$-Galactosidase & + & + & $\mathrm{w}$ & + \\
\hline Arginine aminopeptidase & - & - & + & + \\
\hline Histidine aminopeptidase & - & - & - & + \\
\hline Glycine aminopeptidase & - & + & - & - \\
\hline Predominant menaquinones & $\begin{array}{l}\text { MK-10, MK-11, } \\
\text { MK-12, MK-13 }\end{array}$ & $\begin{array}{c}\text { MK-9, MK-10, } \\
\text { MK-11 }\end{array}$ & $\begin{array}{c}\text { MK-10, MK-11, } \\
\text { MK-12 }\end{array}$ & $\begin{array}{l}\text { MK-10, } \\
\text { MK-11 }\end{array}$ \\
\hline DNA G $+C$ content $(\mathrm{mol} \%)$ & $51 \cdot 1-51 \cdot 3$ & $40 \cdot 0$ & $50 \cdot 5$ & $41 \cdot 1$ \\
\hline
\end{tabular}




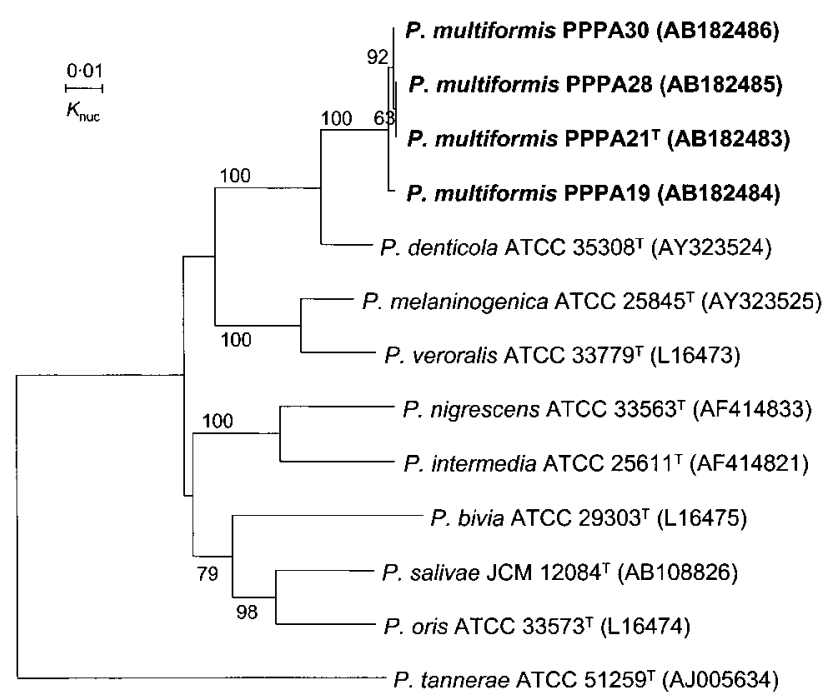

Fig. 1. Phylogenetic tree showing the relationship between $P$. multiformis sp. nov. and related species. The tree was constructed by the neighbour-joining method based on 16S rRNA gene sequences. Numbers at nodes indicate bootstrap values for each node, out of 100 bootstrap resamplings. Bar, 0.01 substitutions per nucleotide position. An extended neighbourjoining tree is available as Supplementary Fig. B in IJSEM Online.

of these four strains from $P$. denticola JCM 8528 (relatively low DNA relatedness, $\leqslant 28 \%$; Supplementary Table D).

Approximately 1500 bases of the 16S rRNA gene sequence were determined for each of the isolates (strains PPA19, PPPA $21^{\mathrm{T}}$, PPPA28 and PPPA30). For the phylogenetic analysis, $1379 \mathrm{bp}$ (positions 34-1391, Escherichia coli numbering system) sequences of each species were used. $16 \mathrm{~S}$ rRNA gene sequence analysis showed that each of the isolates was a species of the genus Prevotella (Fig. 1 and Supplementary Fig. B). These four strains were related to $P$. denticola with about $95 \%$ similarity. The levels of sequence similarity among the four strains were above $99 \cdot 7 \%(99 \cdot 7-100 \%)$. In addition, the isolates were related to Prevotella sp. oral clone AO036 (Paster et al., 2001) with about $96 \%$ similarity. Moreover, the $16 \mathrm{~S}$ rRNA gene sequences were determined for the different sizes of colony for each isolate. $16 \mathrm{~S}$ rRNA gene sequence analysis revealed no differences between the cells forming the large and small colonies. Furthermore, the phenotypic and biochemical characteristics (determined using API 20A, API ZYM and API An-Ident) of colonies of different sizes were found to be the same. These findings indicated that only a single micro-organism was present.

On the basis of the above-mentioned findings and the $16 \mathrm{~S}$ rRNA gene sequence analysis, we propose a novel Prevotella species, Prevotella multiformis sp. nov., for these four strains. Differential characteristics of Prevotella multiformis sp. nov. and some related Prevotella species are shown in Table 2.

\section{Description of Prevotella multiformis sp. nov.}

Prevotella multiformis (mul.ti.for'mis. L. fem. adj. multiformis many-shaped, multiform).

Cells are obligately anaerobic, non-spore-forming, nonmotile, Gram-negative rods $(0.5-0.8 \times 1.6-6.6 \mu \mathrm{m})$ or cocci (coccobacilli) $(0 \cdot 8 \times 0 \cdot 9-1 \cdot 0 \mu \mathrm{m})$. Colonies are $1-$ $2 \mathrm{~mm}$ in diameter, grey to light brown, circular, entire, slightly convex and smooth on EG agar plates. Colonies of different sizes are detected on EG agar plates. Cells forming large colonies are cocci, whereas those forming small colonies are cocci and rods. Growth is inhibited in the presence of $20 \%(\mathrm{w} / \mathrm{v})$ bile. Acid is produced from Dcellobiose, glucose, glycerol, lactose, maltose, D-mannose, D-raffinose and sucrose. Acid is not produced from Larabinose, D-mannitol, D-melezitose, D-rhamnose, salicin, D-sorbitol, D-trehalose or D-xylose. Aesculin is not hydrolysed. Indole is not produced. Gelatin is digested. Catalase and urease are not produced. The major end-products [from $1 \%(\mathrm{w} / \mathrm{v})$ peptone $/ 1 \%(\mathrm{w} / \mathrm{v})$ yeast extract $/ 1 \%(\mathrm{w} / \mathrm{v})$ glucose broth cultures] are succinic and acetic acids; small amounts of isovaleric acid are also produced. Malate dehydrogenase and glutamate dehydrogenase are present, whereas G6PDH and 6PGDH are absent. Both nonhydroxylated and 3-hydroxylated long-chain fatty acids are present. The major cellular fatty acids are anteiso- $15: 0$, iso-15:0, iso-3-OH-17:0 and $18: 1 \omega 9 c$. The principal respiratory quinones are menaquinones MK-11 (49-55\%) and MK-12 (29-31\%). Minor menaquinones are MK-8 (1\%), MK-9 (1\%), MK-10 (8-12\%) and MK-13 (2-3\%). The DNA G + C content of the type strain is $51 \cdot 1 \mathrm{~mol} \%$.

The type strain is strain PPPA $21^{\mathrm{T}}\left(=\mathrm{JCM} 12541^{\mathrm{T}}=\mathrm{DSM}\right.$ $16608^{\mathrm{T}}$ ), which was isolated from subgingival plaque from a patient with chronic periodontitis.

\section{Acknowledgements}

We are grateful to Professor Dr H. G. Trüper, University of Bonn, Germany, for his suggestions regarding nomenclature. This work was supported, in part, by a Grant-in-Aid for Scientific Research (no. 13672202) from the Japan Society for the Promotion of Science (to M. S.).

\section{References}

Bailey, G. D. \& Love, D. N. (1995). Glucose 6-phosphate dehydrogenase and 6-phosphogluconate dehydrogenase activities and glucose utilization by species within the genera Bacteroides, Prevotella, and Porphyromonas. Int J Syst Bacteriol 45, 246-249.

Dellinger, C. A. \& Moore, L. V. H. (1986). Use of the RapID-ANA system to screen for enzyme activities that differ among species of bile-inhibited Bacteroides. J Clin Microbiol 23, 289-293.

Ezaki, T., Hashimoto, Y. \& Yabuuchi, E. (1989). Fluorometric deoxyribonucleic acid-deoxyribonucleic acid hybridization in microdilution wells as an alternative to membrane filter hybridization in which radioisotopes are used to determine genetic relatedness among bacterial strains. Int J Syst Bacteriol 39, 224-229. 
Felsenstein, J. (1985). Confidence limits of phylogenies: an approach using the bootstrap. Evolution 39, 783-791.

Gharbia, S. E. \& Shah, H. N. (1991). Pathways of glutamate catabolism among Fusobacterium species. J Gen Microbiol 137, 1201-1206.

Holdeman, L. V., Cato, E. P. \& Moore, W. E. C. (1977). Anaerobic Laboratory Manual, 4th edn. Blacksburg, VA: Virginia Polytechnic Institute and State University.

Kimura, M. (1980). A simple method for estimating evolutionary rates of base substitutions through comparative studies of nucleotide sequences. J Mol Evol 16, 111-120.

Komagata, K. \& Suzuki, K. (1987). Lipid and cell-wall analysis in bacterial systematics. Methods Microbiol 19, 161-207.

Kuykendall, L. D., Roy, M. A., O'Neill, J. J. \& Devine, T. E. (1988). Fatty acids, antibiotic resistance, and deoxyribonucleic acid homology groups of Bradyrhizobium japonicum. Int J Syst Bacteriol 38, 358-361.

Laughon, B. E., Syed, S. A. \& Loesche, W. J. (1982). API ZYM system for identification of Bacteroides spp., Capnocytophaga spp., and spirochetes of oral origin. J Clin Microbiol 15, 97-102.

Marmur, J. (1961). A procedure for the isolation of deoxyribonucleic acid from microorganisms. J Mol Biol 3, 208-218.

Mayberry, W. R., Lambe, D. W., Jr \& Ferguson, K. P. (1982). Identification of Bacteroides species by cellular fatty acid profiles. Int J Syst Bacteriol 32, 21-27.

Miller, L. T. (1982). Single derivatization method for routine analysis of bacterial whole-cell fatty acid methyl esters, including hydroxy acids. J Clin Microbiol 16, 584-586.

Miyagawa, E., Azuma, R. \& Suto, T. (1979). Cellular fatty acid composition in gram-negative obligately anaerobic rods. J Gen Appl Microbiol 25, 41-51.

Paster, B. J., Boches, S. K., Galvin, J. L., Ericson, R. E., Lau, C. N., Levanos, V. A., Sahasrabudhe, A. \& Dewhirst, F. E. (2001). Bacterial diversity in human subgingival plaque. J Bacteriol 183, 3770-3783.

Saito, H. \& Miura, K. (1963). Preparation of transforming deoxyribonucleic acid by phenol treatment. Biochim Biophys Acta 72, 619-629.

Saitou, N. \& Nei, M. (1987). The neighbor-joining method: a new method for reconstructing phylogenetic trees. Mol Biol Evol 4, 406-425.

Sakamoto, M., Huang, Y., Umeda, M., Ishikawa, I. \& Benno, Y. (2002a). Detection of novel oral phylotypes associated with periodontitis. FEMS Microbiol Lett 217, 65-69.
Sakamoto, M., Suzuki, M., Umeda, M., Ishikawa, I. \& Benno, Y. (2002b). Reclassification of Bacteroides forsythus (Tanner et al. 1986) as Tannerella forsythensis corrig., gen. nov., comb. nov. Int J Syst Evol Microbiol 52, 841-849.

Sakamoto, M., Suzuki, M., Huang, Y., Umeda, M., Ishikawa, I. \& Benno, Y. (2004). Prevotella shahii sp. nov. and Prevotella salivae sp. nov., isolated from the human oral cavity. Int $J$ Syst Evol Microbiol 54, 877-883.

Shah, H. N. (1992). The genus Bacteroides and related taxa. In The Prokaryotes, 2nd edn, pp. 3593-3607. Edited by A. Balows, H. G. Trüper, M. Dworkin, W. Harder \& K. H. Schleifer. New York: Springer.

Shah, H. N. \& Collins, M. D. (1980). Fatty acid and isoprenoid quinone composition in the classification of Bacteroides melaninogenicus and related taxa. J Appl Bacteriol 48, 75-87.

Shah, H. N. \& Collins, M. D. (1983). Genus Bacteroides. A chemotaxonomical perspective. J Appl Bacteriol 55, 403-416.

Shah, H. N. \& Collins, M. D. (1988). Proposal for reclassification of Bacteroides asaccharolyticus, Bacteroides gingivalis, and Bacteroides endodontalis in a new genus, Porphyromonas. Int J Syst Bacteriol 38, 128-131.

Shah, H. N. \& Collins, M. D. (1989). Proposal to restrict the genus Bacteroides (Castellani and Chalmers) to Bacteroides fragilis and closely related species. Int J Syst Bacteriol 39, 85-87.

Shah, H. N. \& Collins, M. D. (1990). Prevotella, a new genus to include Bacteroides melaninogenicus and related species formerly classified in the genus Bacteroides. Int J Syst Bacteriol 40, 205-208.

Slots, J. (1981). Enzymatic characterization of some oral and nonoral gram-negative bacteria with the API ZYM system. J Clin Microbiol 14, 288-294.

Tamaoka, J. \& Komagata, K. (1984). Determination of DNA base composition by reversed-phase high-performance liquid chromatography. FEMS Microbiol Lett 25, 125-128.

Tanner, A. C. R., Strzempko, M. N., Belsky, C. A. \& McKinley, G. A. (1985). API ZYM and API An-Ident reactions of fastidious oral gram-negative species. J Clin Microbiol 22, 333-335.

Thompson, J. D., Higgins, D. G. \& Gibson, T. J. (1994). CLUSTAL W: improving the sensitivity of progressive multiple sequence alignment through sequence weighting, position-specific gap penalties and weight matrix choice. Nucleic Acids Res 22, 4673-4680. 